Editor's Note: These short reviews of a recent paper in the Journal, written exclusively by graduate students or postdoctoral fellows, are intended to mimic the journal clubs that exist in your own departments or institutions. For more information on the format and purpose of the Journal Club, please see http://www.jneurosci.org/misc/ifa_features.shtml.

\title{
Turning on the Spotlight: Do Attention and Luminance Contrast Affect Neuronal Responses in the Same Way?
}

\author{
Michael J. Proulx \\ Institute of Experimental Psychology, Heinrich-Heine-University, Düsseldorf, D-40225 Düsseldorf, Germany \\ Review of Lee et al. (http://www.jneurosci.org/cgi/content/full/27/36/9632)
}

The environment supplies an overwhelming richness of stimulation. In the case of vision, at any given moment information is coming from all areas of the visual field and is represented by multiple features that change from one moment to the next and with each fixation of the eye. The properties of attention allow us to selectively perceive some stimuli and not others, such that one can efficiently process and respond to relevant information and inhibit momentarily irrelevant information. The neural basis of attention has been described as analogous to how a change in luminance level, or contrast, affects neuronal responses. If a stimulus in the receptive field of a neuron evokes a response from that cell, then increasing the brightness of that stimulus will increase the response. Similarly, if a stimulus in the receptive field of a neuron evokes a response in the absence of attention to that stimulus, then directing visual attention to that stimulus will increase the response of the cell (Reynolds et al., 2000).

How strong is this analogy between contrast and attention and their effects on neuronal response? Lee et al. (2007), in The Journal of Neuroscience, report an important constraint on the similarity between attention and contrast. Most stud-

Received Sept. 25, 2007; revised 0ct. 9, 2007; accepted 0ct. 10, 2007.

Correspondence should be addressed to Michael Proulx, Institute of Experimental Psychology II, Building 23.03, 00.48, Universitätsstrasse 1, D-40225 Düsseldorf, Germany. E-mail: Michael.Proulx@ uni-duesseldorf.de.

D0I:10.1523/JNEUROSCI.4378-07.2007

Copyright $\odot 2007$ Society for Neuroscience $\quad$ 0270-6474/07/2713043-02\$15.00/0 ies that have examined the effects of visual attention have focused on the magnitude of neuronal responses. By this measure, the effects of attention are similar to the effects of changes in contrast. However, one can also examine the effects of attention and contrast on the latency of neuronal responses. Increasing the brightness, or contrast, of a stimulus triggers neuronal responses with a shorter latency starting as early as the retina, and continuing through to the cortex. However, few studies have reported whether spatial attention has effects on latency.

Lee et al. (2007) manipulated stimulus contrast and spatial attention independently to observe their independent and combined effects on neuronal responses in visual area V4. The task required a macaque monkey to monitor one of two streams of stimuli located at the left and right of fixation [Lee et al. (2007), their Fig. 1 (http://www.jneurosci.org/cgi/ content/full/27/36/9632/F1)]. One stream was located within the spatial receptive field of the neuron being recorded, and the other was outside it. The stream of Gabor stimuli (sine-wave gratings in a Gaussian window) appeared on both sides at four different levels of contrast. With this elegant manipulation, the neuronal responses could be analyzed for the effect of contrast, the effect of attention, and the interaction of contrast and attention.

The responses of individual neurons exhibited evidence both against and in support of the analogy between contrast and attention [Lee et al. (2007), their Fig 2 (http://www.jneurosci.org/cgi/content/ full/27/36/9632/F2), compare $a$ and $d$ ]. Although both attention and contrast increased the magnitude of neuronal responses, attention to the receptive field of that cell yielded a change in latency in one cell but not the other. An analysis of the population of V4 neurons was more definitive. The average responses from the population revealed that the overall effect of attention on latency was not significant [Lee et al. (2007), their Fig. 3 (http:// www.jneurosci.org/cgi/content/full/27/ $36 / 9632 / F 3)]$. Thus the population of neurons in V4 did not respond with a shorter latency as a function of spatial attention but did respond with a shorter latency as a function of increased contrast.

The analogy between contrast and attention may therefore not apply to spatial attention. However, attention is not a singular entity. For over a century, psychological research on attention has described two components, with multiple names that basically describe this same thing: active versus passive (James, 1890/1950), sustained versus transient (Nakayama and Mackeben, 1989), or top-down versus bottom-up attention (Egeth and Yantis, 1997). The form of spatial attention manipulated by Lee et al. (2007) is of the active, sustained, and top-down type. Although this form of attention might not affect neuronal responses in the same manner as contrast, there is a suggestion in the psychophysical literature that con- 
trast and the passive, transient and bottom-up, type of attention may in fact affect neuronal responses in the same manner (Proulx and Egeth, 2007).

One example of the psychophysical evidence that distinguishes sustained versus transient attention is the study by $\mathrm{Na}$ kayama and Mackeben (1989). These authors reported that a sustained cue (a box surrounding a stimulus), which is always present at a location where the target will appear, enhanced target discrimination performance. The increase in response magnitude as a function of spatial attention in V4 might be the neural correlate of this effect (Lee et al., 2007). Similarly, Nakayama and Mackeben also reported that a transient cue at the target location leads to enhanced target discrimination performance. The time course of the sustained and transient forms of attention differentiated the two. The transient component of attention was fastacting and short-lived; however, the sustained component of attention was slower to respond and could be maintained longer than the transient one. The shorter latency of the transient component suggests that it is more analogous to the effect of contrast on the latency of neuronal responses than that of the sustained component. Visual search studies that have manipulated stimulus contrast, rather than providing an additional cue, have found effects similar to those of the transient component (Proulx and Egeth, 2007).

The task used by Lee et al. could be modified as depicted in Figure 1 to mimic the psychophysical studies of transient, or bottom-up, attention. Rather than the monkey sustaining spatial attention at
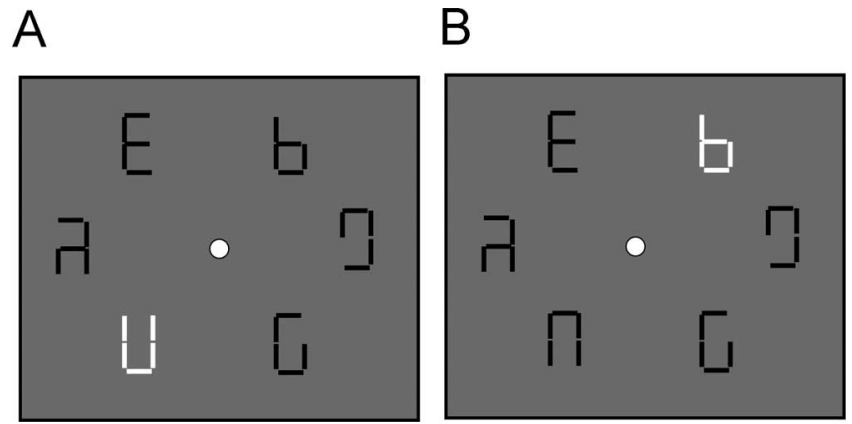

Figure 1. This is a depiction of the proposed free-viewing visual search task to examine the impact of transient attention on the latency of neuronal responses. The search target is an upright or upside-down $\mathrm{U}$, and the animal is to report the orientation of the target (cf. Oristaglio et al., 2006). With the example set size of six as shown, the $U$ target would also be the brightest stimulus on one of six trials $(\boldsymbol{A})$, and a nontarget would be the brightest on five of six trials $(\boldsymbol{B})$, to render the brightness of the stimuli irrelevant for the search task.

one location, the target location could be uncertain and determined by the identity of the stimulus (e.g., the lines that form a $\mathrm{U}$ in Fig. 1). The response times of the monkey could then be related to both the magnitude and the latency of neuronal responses when the bright target versus the normal contrast target appears in the spatial receptive field of a cell. Thus the analogy relating contrast to attention could be tested for the transient, bottom-up, and passive component of attention.

The independent manipulation of contrast and sustained attention has revealed, for the first time, that contrast and sustained attention do not impact the latency of neuronal response in the same way. Whether transient attention retains this similarity remains to be seen and is fodder for additional illuminating studies that bring the psychological and neurophysiological literature together in exciting ways.

\section{References}

Egeth H, Yantis S (1997) Visual attention: control, representation, and time course. Annu Rev Psychol 48:269-297.

James W (1890/1950) The principles of psychology. New York: Dover.

Lee J, Williford T, Maunsell JHR (2007) Spatial attention and the latency of neuronal responses in macaque area $\mathrm{v} 4$. J Neurosci 27:9632-9637.

Nakayama K, Mackeben M (1989) Sustained and transient components of focal visual attention. Vision Res 29:1631-1647.

Oristaglio J, Schneider DM, Balan PF, Gottlieb J (2006) Integration of visuospatial and effector information during symbolically cued limb movements in monkey lateral intraparietal area. J Neurosci 26: $8310-8319$.

Proulx M, Egeth H (2007) Biased competition and visual search: the role of luminance and size contrast. Psychol Res, in press. Attention increases sensitivity of V4 neurons. Neuron 26:703-714.
Reynolds JH, Pasternak T, Desimone R (2000) 